\title{
O não-lugar da comunicação comunitária: relações públicas e construção dialógica no programa "Minha casa, minha vida"
}

The non-place of community communication: public relations and dialogue construction in the "Minha casa, minha vida" program

El no-lugar de la comunicación comunitaria: relaciones públicas y construcción dialógica en el programa "Minha casa, minha vida"

Rodrigo Maurício Freire Soares

- Mestre em Desenvolvimento e Gestão Social pela Universidade Federal da Bahia (UFBA)

- Especialista em Gestão da Comunicação Organizacional Integrada pela UFBA

- Graduado em Relações Públicas pela Universidade do Estado da Bahia (Uneb)

- Professor substituto na Uneb

- Coordenador de projetos de extensão no Centro Interdisciplinar de Desenvolvimento e Gestão Social (CIAGS/UFBA)

- E-mail:rmsoares@uneb.br 


\section{Resumo}

Como fazer comunicação comunitária em "não-lugares" compostos por "não-comunidades"? Essa é a pergunta que norteia a pesquisa realizada em um conjunto residencial do rograma "Minha casa, minha vida", em Salvador (BA). 0 sentido de pertencimento nulo dos indivíduos a esse território resulta em um espaço de conflitos em que a comunicação comunitária encontra frágil ancoragem. Este artigo busca contribuir para a área de relações públicas ao tratar de uma construção dialógica em comunidade a partir de um modelo de gestão relacional.

\section{PALAVRAS CHAVE: COMUNICAÇÃO COMUNITÁRIA •IDENTIDADES•ESTRATÉGIAS.}

\section{Abstract}

How to establish community communication in "non-places" composed of "non-communities"? This is the question driving the research developed residential project of the "Minha casa, minha vida" (My house, my life) program in the city of Salvador, State of Bahia. The inexistent individuals' sense of belonging to this territory results in an environment of conflicts where community communication finds weak support. This article aims to contribute to the area of public relations by dealing with dialogue construction in a community, based on a relational management model.

\section{KEYWORDS: COMMUNITY COMMUNICATION •IDENTITIES・STRATEGIES.}

\section{Resumen}

¿Cómo lograr comunicación comunitaria en 'no-lugares' compuestos por 'no-comunidades'? Esa es la pregunta que conduce la investigación realizada en un conjunto residencial del programa habitacional "Minha casa, minha vida" (Mi casa, mi vida) en Salvador (BA). El sentido de pertenencia nulo de las personas respecto a ese territorio resulta en un espacio de conflictos donde la base de comunicación comunitaria es frágil. Ese artículo busca contribuir para el área de las relaciones públicas por medio del tratamiento de una construcción dialógica en comunidad desde un modelo de gestión relacional. 
$\mathrm{E}$ mpreendimentos habitacionais do programa Minha Casa, Minha Vida são territórios que enunciam uma urbanidade futura. São partes integrantes de uma política habitacional responsável pelo adensamento populacional de novas áreas da cidade que se estruturam como vetores de expansão e desenvolvimento. São urbanidades futuras que se apresentam a partir da aglomeração de moradores que compartilharão espaços heterogêneos compostos por múltiplas identidades. Como todo novo território, são espaços de conflitos, disputas e tensões de poderes em diversas escalas, aos quais logo é atribuído o signo da "comunidade".

A utilização do termo "comunidade" evoca o resgate de uma sociabilidade positiva e idealizada, um estado de partilha de valores, proteção e costumes a que Bauman (2003) qualificou como indicativos de uma "comunidade imaginada". Estar em "comunidade" é, antes de tudo, uma definição simbólica por distanciar-se da dimensão reducionista da espacialidade, e por dialogar diretamente com as noções de pertencimento. Por outro lado, é recorrente a referência a "comunidades" como grupos em situação de vulnerabilidade social. Os bairros nobres são compostos por "moradores", enquanto os bairros da periferia, por "comunidades". São estas as terminologias forjadas despretensiosamente e calcadas nos significantes e significados que atribuem sentido aos territórios.

O programa Minha Casa, Minha Vida estrutura-se a partir da criação de conjuntos habitacionais cuja "aura comunitária" repousa unicamente na espacialidade, uma vez que as unidades habitacionais são sorteadas entre famílias que vêm de distintas realidades e culturas. 0 pertencimento nulo somado a um mosaico fractal de culturas resulta em um espaço de tensões e conflitos onde a comunicação comunitária se virtualiza como intenção inicial, cuja ancoragem se dá em um campo que the confere pouca aderência.

0 presente texto traz consigo a pergunta: Como fazer comunicação comunitária em "não-lugares" compostos por "nãocomunidades"? Considerando que a espacialidade não determina um status de comunidade e que tais empreendimentos integram múltiplas identidades reunidas compulsória e aleatoriamente, resta apenas o senso comum que atribui ao território o caráter de comunitário tão somente pela condição social dos seus moradores. Está-se aqui distante dessa abordagem simplista pautada apenas na condição social, entendendo o público como uma "não-comunidade" desde o início das ações do projeto. Nesse contexto, as ações de comunicação e relações públicas comunitárias enfrentaram um desafio adicional, 0 de implementar técnicas e de efetuar uma abordagem junto aos referidos públicos de forma quase laboratorial, em que se testem metodologias, práticas e percursos formativos.

Para que o desenvolvimento desses novos recortes urbanos se dê de maneira integrada e sustentável, énecessário pensar projetos de futuro que questionem a lógica desigual vigente. Trata-se de um olhar da comunicação para esses redutos habitacionais "desmidiatizados", cujas lógicas tradicionais de ação comunitária se mostram superficiais, frágeis e inconsistentes.

\section{COMUNIDADE, COMUNICAÇÃO COMUNITÁRIA E NÃO-LUGAR: REVISITANDO CONCEITOS}

A discussão sobre o tema da comunicação comunitária está presente amplamente em obras como as de Ferreira (1995), Peruzzo (2004), Kunsch \& Kunsch (2007) e Miani (2007), sendo apresentado um conjunto de características que atribuem a essa tipologia de comunicação a sua insígnia comunitária, tais como os vínculos construídos, a noção de pertencimento e a partilha de objetivos e interesses. Algumas realidades conferem complexidade a essa categorização e desubstancializam 0 termo "comunidade" sob o ponto de vista ontológico. 
Esposito (2007) nos apresenta uma definição de comunidade como um espaço de clausura, em que cada indivíduo tem em si uma obrigação de dar algo em prol de um coletivo, perfazendo um estado de cumplicidade pela ausência e pela dívida. Esse percurso implica uma condição contínua de déficit entre os seus membros, o que resulta em uma dificuldade da afirmação do indivíduo como sujeito. As características aqui apresentadas desse público (moradores do empreendimento) advêm de uma origem compulsória, fruto de uma política habitacional que cria novas urbanidades e, neste caso, é responsável pela criação do que chamo aqui de "não-comunidades".

Ser uma "não-comunidade" não é, no contexto desta análise, fruto da quebra gradual dos vínculos sociais que tipificam a pós-modernidade e a sua fragmentação relacional. Entende-se essa condição de "não-comunidade" como o estado de uma coletividade criada superficialmente, neste caso por um programa habitacional federal que reúne milhares de pessoas em espaços urbanos densamente povoados. E como um fenômeno etéreo e artificial, essas relações entre os indivíduos podem ser consideradas como frágeis e inconsistentes em um primeiro momento. Como afirma Sodré (2002, p. 223),

a sociologia pode tentar abordar, mas a comunidade não é simplesmente agregação, a junção de pessoas. É o laço atrativo. E esse laço é atrativo, é a obrigação simbólica originária, que faz nascer uma dívida simbólica com o grupo social. (...) São compromissos sociais de vida e morte. Isso eu chamo de vínculo social.

No referido território, observa-se a existência da "comunidade dos sem-comunidade" ou uma comunidade daqueles renegados socialmente, desmotivados a fazer a "obra da comunidade" e se reconhecerem enquanto tais (enquanto comunitários). 0 Residencial Bosque das Bromélias como um "não-lugar" (Augé, 2011), justifica-se por ser um espaço não-identitário, nãohistórico e não-relacional. A condição espacial, de desconexão com a cidade e com os serviços públicos essenciais, é também responsável por provocar uma perda do sentido de grupo e sociedade, prevalecendo apenas o indivíduo solitário.

\section{DELIMITANDO O ESPAÇO: CONTEXTUALIZAÇÃO DO NÃO-LUGAR' E DA AUSÊNCIA DOS VÍNCULOS DE COMUNIDADE}

Em 2013, a Universidade Federal da Bahia (UFBA) apresentou uma proposta para uma chamada pública lançada pela Caixa Econômica Federal, que tinha como objeto a elaboração de um modelo de desenvolvimento territorial em um empreendimento do programa Minha Casa, Minha Vida. O projeto submetido e aprovado, intitulado "Minha Casa, Nossas Vidas", foi uma iniciativa do Centro Interdisciplinar de Desenvolvimento e Gestão Social da Universidade Federal da Bahia (CIAGS/UFBA), tendo como objetivo a construção e testagem de tecnologias sociais no âmbito da estratégia de Desenvolvimento Integrado e Sustentável de Territórios. 0 projeto teve início em janeiro de 2014 e encerrou as suas atividades em fevereiro de 2017 , tendo tido como abrangência geográfica o empreendimento Bosque das Bromélias.

O Empreendimento Residencial Bosque das Bromélias compreende seis conjuntos habitacionais e está localizado no município de Salvador, nos limites deste com o município vizinho, Lauro de Freitas. A área onde o residencial está situado fica fora do perímetro urbano do município de Salvador, o que dificulta o acesso da população a serviços básicos. 0 bairro mais próximo, São Cristóvão, fica a cinco quilômetros e a oferta de serviços públicos é escassa. Não existem equipamentos de saúde, educação e segurança pública no entorno do empreendimento. 0 Residencial Bosque das Bromélias é composto por 120 edifícios, com um total de 2.400 apartamentos. Considerando o número de famílias residentes e o número médio de quatro moradores por unidade familiar presente no diagnóstico realizado, está-se falando de aproximadamente 9.600 pessoas, o que corresponde

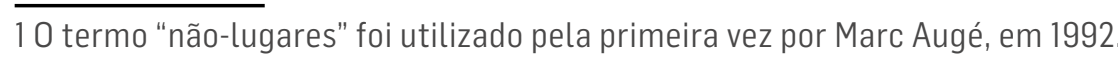




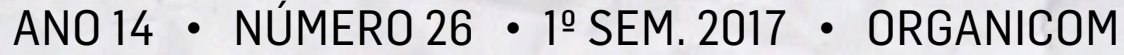 \\ O NÃO-LUGAR DA COMUNICAÇ̃̃O COMUNITÁRIA: RELAÇÕES PÚBLICAS E CONSTRUÇÃO DIALÓGICA NO PROGRAMA "MINHA CASA, MINHA VIDA"}

ao quantitativo populacional de pequenos municípios brasileiros. A ausência desses elementos de inclusão distancia essas pessoa da moradia no seu conceito pleno de dignidade e cidadania, não despertando nelas o sentimento de pertencimento e identidade com o lugar, pressuposto básico para o vínculo e afeto com o espaço da vida e das relações sociais.

Figura 1: Empreendimento Minha Casa, Minha Vida - Bosque das Bromélias.

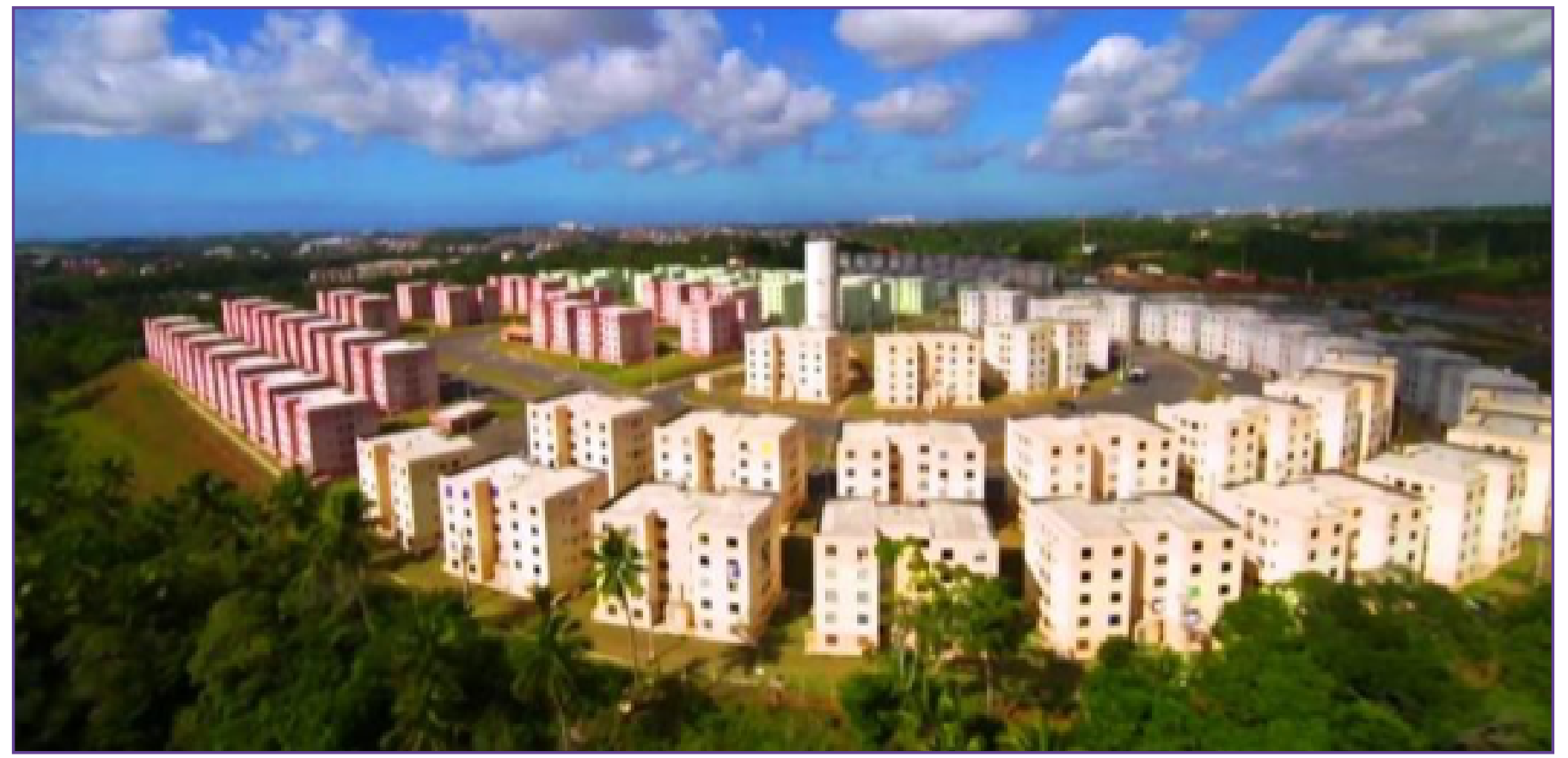

Imagem: Acervo do Projeto, 2014.

Concebe-se um território como um espaço geograficamente definido, caracterizado por aspectos multidimensionais (ambiente, economia, cultura, entre outros) onde se podem distinguir elementos que indicam identidade e coesão. Territórios podem ser dinamizados por projetos de desenvolvimento, que se iniciam por concepções e desenhos do imaginário e devem se traduzir em planos e ações efetivas. Territórios têm os mesmos traços distintos de complexidade, diversidade, singularidade, contradição e ambiguidade. No território do Bosque das Bromélias estão reunidos grupos advindos de diferentes movimentos sociais, de diferentes acampamentos do movimento dos sem-teto e também do movimento sem-terra.

0 título do Projeto "Minha Casa, Nossas Vidas" foi escolhido após algumas visitas prévias ao empreendimento e a percepção da equipe sobre a ausência de um sentimento de pertencimento. A dimensão da posse da unidade familiar ("minha casa") depende diretamente de um modelo coletivo de sociabilidade ("nossas vidas"), pois o público beneficiário desses imóveis é constituído por indivíduos que vêm de comunidades reais do ponto de vista conceitual, em que a existência de uma rede de proteção social é característica sempre presente.

O objetivo do projeto da UFBA foi a elaboração de um plano de desenvolvimento territorial que contemplasse as áreas de cultura, meio ambiente, formação profissional, saúde e lazer e governança. Para chegar a esse resultado, o projeto demandou um conjunto de ações de comunicação como eixo transversal, valendo-se diretamente da estratégia de mobilização de relacionamento com os distintos públicos presentes na literatura de relações públicas.

Há uma prerrogativa na abordagem aqui utilizada que se refere às relações de significação a partir dos lugares de fala dos indivíduos. Nesse sentido, buscou-se evitar a transposição de abordagens de relações públicas consolidadas em outros contextos, sobretudo o norte-americano, em que prevalecem os objetivos dos interesses organizacionais e certos pressupostos de uniformidade de poder entre os públicos. 
Tornam-se especialmente relevantes as manifestações discursivas que conformam as identidades dos diferentes atores sociais. Tal perspectiva encontra abrigo teórico em uma visão de sentido-identidade que prioriza "as relações públicas e a sociedade e para as consequências desejadas e não desejadas das ações de relações públicas nesse contexto" (Pereira, 2017, p. 107).

\section{ESTRATÉGIAS DE COMUNICAÇÃO IMPLEMENTADAS NO BOSQUE DAS BROMÉLIAS}

Como primeira ação do projeto, foi realizado um diagnóstico censitário junto a 2.400 famílias residentes no empreendimento, visando delinear o perfil socioeconômico desse público. 0 diagnóstico contou com sessenta questões divididas em cinco blocos: 1) perfil dos membros das famílias (gênero, faixa etária, escolaridade e renda); 2) interesses e vocações locais; 3) demandas por formação e capacitação; 4) relacionamento entre os moradores; e 5) expectativas sobre o futuro. Os resultados desse diagnóstico subsidiaram um momento posterior de planejamento, em que se buscou fortalecer o que estamos chamando aqui de uma "gestão relacional", como um modelo de construção dialógica com ampla participação da comunidade.

Logo nas primeiras interações do projeto ficou evidente a não-partilha de vínculos identitários e de comunidade, expressos nas vozes do território: "(...) misturou gente de bairro pobre com morador de rua que não foi educado para viver em condomínio"(Morador 1); "...) ficarem juntos, no mesmo bloco, gente que veio dos bairros com o pessoal das ocupações dos sem-teto não vai dar certo"(Morador 2); "(...) as pessoas saíram da favela mas a favela permanece dentro das pessoas" (Morador 3); ou ainda: "...) colocaram a gente pra morrer aqui, o SAMU² não entra aqui, aqui é lugar nenhum"(Morador 4).

Nesse sentido, o desafio que se apresentava à equipe de comunicação foi: "como potencializar a comunicação e interação entre os diferentes perfis de indivíduos e grupos presentes no empreendimento?" A realização de ações de comunicação se deu prioritariamente pela busca de uma identidade territorial, conjugando atividades voltadas à cultura e à necessidade de se viabilizarem instrumentos alternativos que promovessem o diálogo local. Estabeleceuse uma estratégia de comunicação pautada na participação popular, aproximando a comunicação às culturas e dinâmicas políticas, econômicas e sociais do território.

Como premissa, buscou-se o distanciamento das "receitas" prontas de comunicação comunitária, que invariavelmente versam sobre a criação de jornais comunitários, murais e material informativo impresso como solução técnica desvinculada de uma demanda real. A diretriz que norteou os trabalhos foi o entendimento da comunicação como um ato de gestão relacional, como um resultado de um amplo processo de escuta, em que produtos como uma rádio ou eventos culturais são entendidos como consequência de uma construção coletiva. Essa visão aproxima-se das definições de relações públicas que lhes atribuem uma função mediadora, política e de negociação de sentidos junto aos diversos públicos. Nesse sentido, este texto alinha-se às definições de Grunig e Hunt (1984), que apresentam a função de gestão como procura dialógica do entendimento mútuo entre os diversos públicos, ainda que as simetrias propostas pelo modelo não sejam integralmente aplicáveis ao contexto. Sob uma perspectiva de maior coesão, essa abordagem dialoga diretamente com a escola crítica de relações públicas (Edwards, 2011), por considerar de forma mais contundente as relações de poder locais, a natureza socialmente construída da prática de relações públicas e a "força discursiva" da sociedade (Duhring, 2015).

20 morador relata que o Serviço de Atendimento Móvel de Urgência (Samu) não acessa o referido território, evidenciando a carência local dos serviços públicos, neste caso, de saúde. Atualmente, o Samu 192 atende 75\% da população brasileira em 2921 municípios. 
O percurso metodológico combinou um conjunto de passos interdependentes, tais como a identificação e formação de lideranças locais, a realização das oficinas de governança e organização comunitária e a constituição de estruturas colegiadas de planejamento e gestão do território (fórum e grupos de trabalho). Se estamos falando de uma gestão relacional, ela necessariamente contemplou o fortalecimento das instâncias locais. A dimensão relacional é norteadora das ações, expressa, sobretudo, na criação de ambientes de convivência, interação e desenvolvimento de capacidades, contribuindo para que as pessoas se conhecessem melhor e construíssem vínculos. Esse elemento guardou forte relação com o aumento do capital social local, aspecto fundamental do processo de desenvolvimento e governança do território.

Do ponto de vista da macroestratégia, o projeto entendeu como diretrizes de comunicação o tripé composto pelos seguintes eixos estruturantes do que estamos chamando aqui de gestão relacional:

1) Criação de espaços de interação e construção coletiva, pelo entendimento de que esses espaços são reveladores dos saberes locais (histórias que precedem a ida ao empreendimento, problemas e expectativas atuais, potencialidades e limitações);

2) Posicionamento do empreendimento como um "produtor de conteúdos" e não apenas como o espaço para circulação de informações;

3) Relacionamento do empreendimento com a cidade: a cidade como "público" do empreendimento.

Figura 2: Estratégia de comunicação.

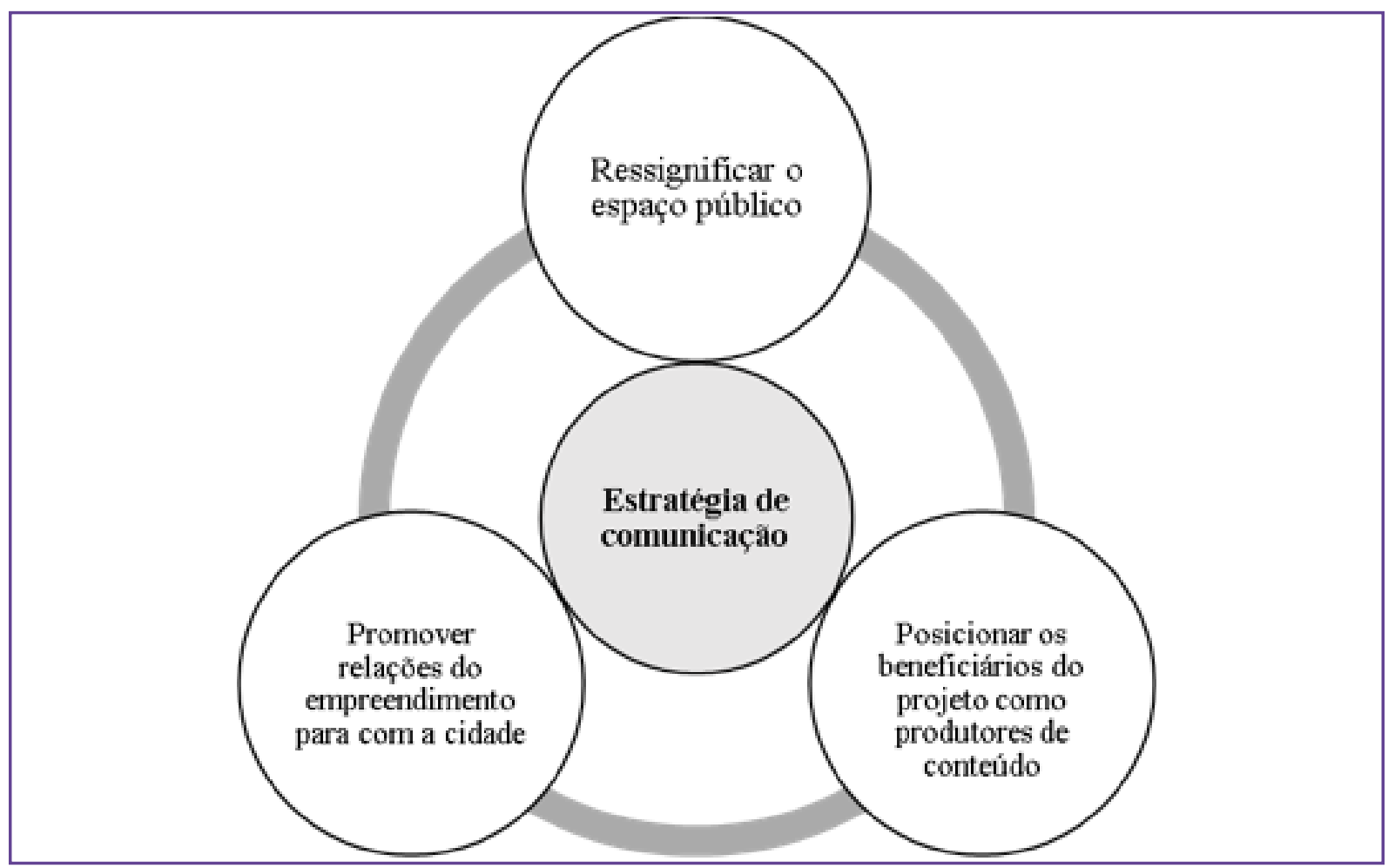

Fonte: Elaboração do autor, 2017.

Sobre os espaços de interação, a lógica da ressignificação do espaço público pauta-se na ocupação do espaço físico/ruas com atividades de lazer, esportivas, intervenções físicas relacionadas a paisagismo e culturais, como fator de visibilidade do projeto e de promoção do diálogo com diferentes moradores. 0 reconhecimento e a ocupação das áreas comuns e ruas públicas é uma estratégia de fortalecimento do sentimento de comunidade. Comumente ouve-se um discurso de 
que a população deve "tirar os jovens das ruas", porém a lógica adotada para essa dimensão da estratégia foi inversa. Considerou-se que era necessário ocupar as ruas com atividades que propiciassem o diálogo, a experiência coletiva e 0 lazer. As ruas devem ser vivas e distantes do discurso de marginalização do espaço comum.

No que tange à vertente de produção de conteúdos, entendemos que era necessário reposicionar o lugar do discurso sobre o Bosque das Bromélias, comumente associado pela mídia soteropolitana a pobreza e marginalização, a um território capaz de produzir conteúdos de relevância cultural e de outras pautas que o distanciassem do discurso policialesco. A comunicação feita "com" e "para a comunidade" alinha-se a uma estratégia de emancipação crítica e a autonomia dos indivíduos. Nesse contexto, a informação ou o conteúdo produzido tiveram essencialmente um caráter "hiperlocal", aquele conteúdo produzido a partir do que acontece na rua do bairro, na praça, na vizinhança.

Um ensinamento relevante, presente na trajetória dessa experiência, diz respeito à importância da aproximação entre os moradores e a cidade como fator de valorização, autoestima e integração cidadã. Como se sabe, os locais onde passaram a residir são, por via de regra, isolados fisicamente e estigmatizados socialmente. Sendo os empreendimentos residenciais do Minha Casa, Minha Vida considerados como territórios de chegada (Fischer; Silva; Soares, 2015) cujas características marcantes são o baixo nível de pertencimento e coesão social e a inserção urbana precária, faz-se mister pensar alternativas para a efetiva inserção desses empreendimentos na dinâmica da cidade. Nesse sentido, a integração com a cidade apresentou-se como um caminho para o fortalecimento de uma identidade territorial. Tal integração se deu a partir de um conjunto articulado de ações com múltiplos fluxos (empreendimentos-território; territórioempreendimentos; empreendimento-empreendimento; território-território; e assim por diante).

\section{AS AÇÕES DE COMUNICAÇÃO POR EIXOS ESTRATÉGICOS: DESCRIÇÃO E RESULTADOS ALCANÇADOS}

Há um fator transversal determinante para a estratégia de comunicação adotada, que é o objetivo do fortalecimento do capital social local. As ações de comunicação estabeleceram uma ambiência para a comunicação comunitária, com a criação de um cenário local em que se observou: 1) subordinação de interesses individuais aos de grupos maiores; 2) trabalho em conjunto, visando a objetivos comuns ou ao benefício mútuo; 3) compartilhamento de valores e normas tanto para a formação de grupos e organizações estáveis, quanto para constituir, compartilhar a gestão; 4) valorização da comunidade de modo a criar e manter contextos, onde se manifestou um ethos de comunidade. As ações apresentadas a seguir constituemse na operacionalização e execução de atividades que espelham as três macrodimensões anteriormente apresentadas. Para cada ação foi estabelecido um plano de trabalho específico, compatível com o escopo e os recursos humanos necessários:

01. Agência de Notícias: estruturação de coletivo de comunicadores para produção de conteúdos e também para mobilização local. 0 grupo formado recebeu capacitação nas áreas de produção de texto, blogues e fotografia;

02. Curso de extensão em comunicação comunitária: ofertadecurso realizado presencialmente noempreendimento, ministrado pelo corpo docente da universidade; 
03. Rádio comunitária: criação de rádio local com gestão horizontal e participativa, como um espaço de trocas/ divulgação de informações, discussões políticas, empoderamento tecnológico e formação técnica;

04. Cineclube: exibição de filmes ao ar livre, tendo os moradores sido os responsáveis pela escolha dos filmes, pela mobilização e pela mediação dos debates que ocorreram após cada sessão, tratando de temas como gênero, violência doméstica, participação, cultura, identidades etc.;

05. Grupo E.I.T.A. Bromélias (Educação, Integração, Teatro e Artes): oficinas de teatro e artesanato com materiais reciclados, envolvendo crianças e adolescentes de 12 a 17 anos de idade, culminando com apresentações públicas do grupo;

06. Plataforma digital \#Co-Labore.vc (<htp://colabore.vc>): ambiente virtual de aprendizagem, comunicação e interação comunitária. 0 \#Co-Labore foi o ambiente virtual de aprendizagem do projeto Minha Casa, Nossas Vidas realizado pela UFBA, tendo-se constituído em uma rede social de ensino;

07. Diagnóstico: levantamento censitário na comunidade, que resultou no mapeamento do perfil dos moradores do Bosque das Bromélias. No total, 2400 unidades familiares foram visitadas, tendo ao final uma amostra válida de 1.152 respondentes;

08. Governança territorial: criação de instância colegiada formada por lideranças locais e por representantes dos diversos grupos de trabalho e de outras instâncias comunitárias (associação, centro comunitários, etc.), com a participação da universidade. 0 fórum se reuniu mensalmente (geralmente no primeiro sábado do mês) para discutir questões relacionadas ao desenvolvimento do território. Esse espaço tem se consolidado com o canal de diálogo das lideranças;

09. Festival de economia criativa: evento com a apresentação dos grupos locais fomentados pelo projeto, nas áreas de teatro, música, gastronomia e dança;

10. Música no Bosque: apresentação do Núcleo Estadual de Orquestras Juvenis e Infantis da Bahia - Neojiba. A apresentação musical do quinteto de sopro do Neojiba teve como objetivo aproximar o empreendimento de um grupo cultural representativo;

11. Clube de trocas: evento no qual interessados em participar levaram objetos até os postos de coleta visando trocálos pela moeda social. Com a moeda social, cada participante poderia adquirir qualquer um dos objetos levados pelos demais moradores no dia do evento. Iniciativa circunscrita à lógica da economia solidária;

12. Biblioteca itinerante: "caminhão-biblioteca" com regularidade quinzenal no território, com 1.611 títulos emprestados/consultados durante 0 ano 2016.

Ao agruparmos a estratégia de comunicação adotada, da comunicação como gestão relacional, nas dimensões da ressignificação do espaço público, produção de conteúdo e promoção de relacionamento com a cidade, tem-se a seguinte configuração: 
Figura 3: Resultados da estratégia de comunicação.

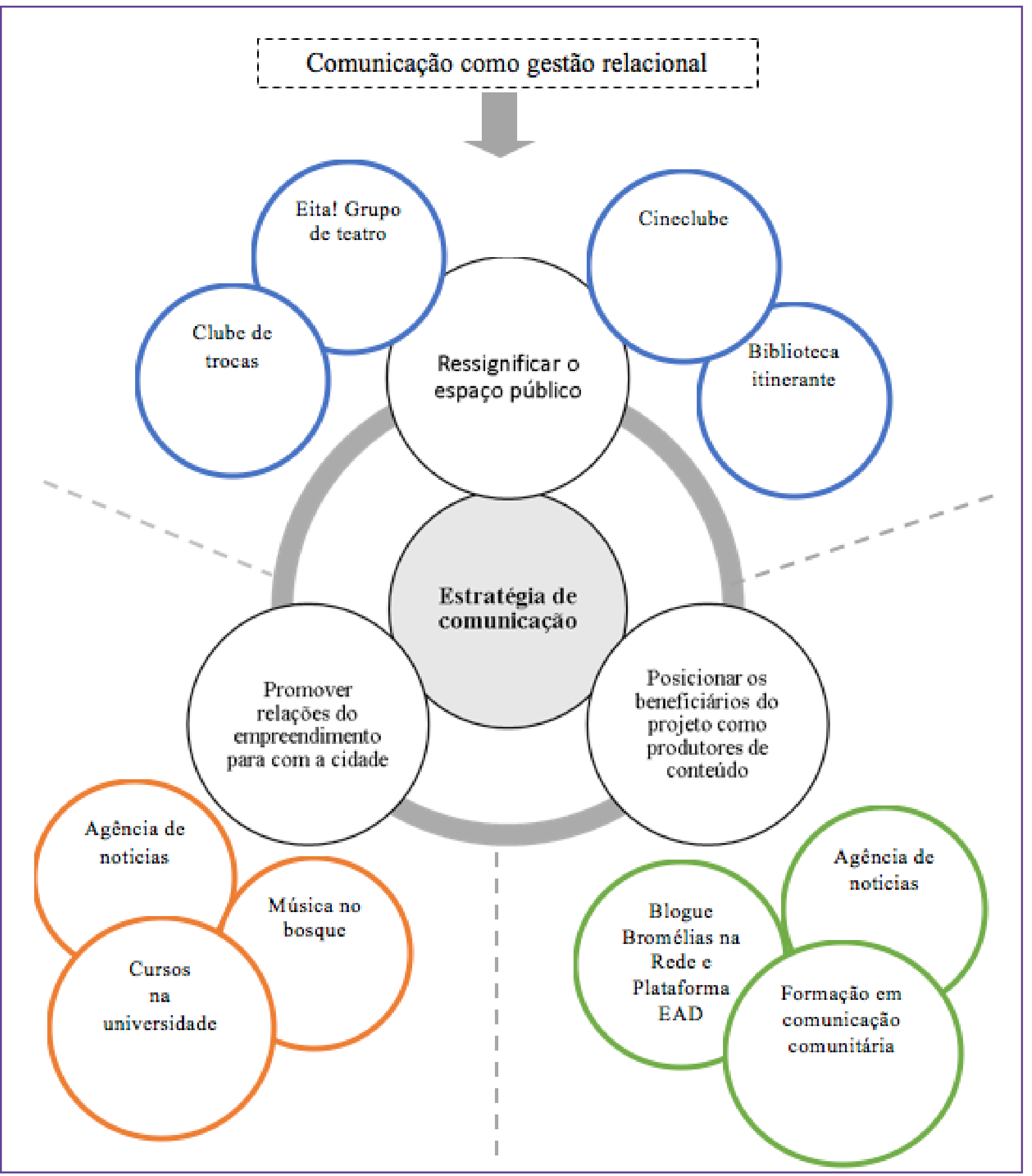

Fonte: Elaboração do autor, 2017.

0 conjunto de atividades implementadas teve um viés endógeno, com enfoque no desenvolvimento das potencialidades dos moradores, bem como um viés exógeno, pautado sobretudo na relação do empreendimento com a cidade e em ações que resgatassem os valores de cidadania, práticas de cooperação, participação e co-criação de soluções.

\section{CONSIDERAÇÕES FINAIS}

Durante muitos anos, as estratégias de desenvolvimento apresentaram invariavelmente um leque de soluções prédeterminadas e verticais, geralmente adaptáveis de forma mínima às realidades locais. Com o passar dos anos, a 
conscientização dos agentes executores e a observância da ineficácia das soluções prontas levou a uma mudança desse cenário, com a predominância de abordagens horizontais construídas com o público-alvo beneficiário da ação. Essa experiência reafirmou a importância da comunicação sob a perspectiva das relações públicas comunitárias, sobretudo ao colocarmos como prerrogativa principal o entendimento do perfil do público e a formatação de ações que contribuíssem para a construção gradativa de uma identidade local.

A simples proximidade geográfica ou residencial (morar no mesmo bairro ou no mesmo condomínio), o fato de pertencer a uma mesma etnia, e assim por diante, não necessariamente garantem a existência de uma "comunidade". As relações afetivas dos indivíduos com seu território e o reconhecimento do outro como parte de um coletivo são premissas para essa idéia de "comunidade", que buscamos fomentar ou fortalecer, entendendo que, nesse contexto, a comunicação assume um papel preponderante e central. A noção de comunidade requer um ambiente de fruição da comunicação, caracterizado pela troca de ideias, pela clareza das demandas locais e pela proposição de ações coletivas.

Ao assumir a "não-comunidade" e entender o empreendimento como um "não-lugar' de uma política habitacional, o foco do trabalho se deu no fomento à criação dessa noção de pertencimento que passou pelo reconhecimento de iniciativas locais já existentes, seu fortalecimento e sua difusão. Essa experiência evidencia um processo de criação de sentidos para uma abordagem de comunicação comunitária, compreendendo-se que é por ela que são fornecidos os subsídios para promoção da participação e da dialogia no processo comunicativo.

Contudo, sob uma perspectiva crítica, ainda que os resultados indiquem o fortalecimento do capital social, faz-se necessário observar que tais intervenções podem significar também fluxos que representam uma forma de "cidadania tutelada". Nesse sentido, é indispensável o entendimento da ação de relações públicas como parte de um processo que deve ter como um dos seus objetivos a apropriação do público beneficiário ao que se produziu em termos de metodologias e tecnologias sociais.

Essa dimensão da interação humana é o que qualifica o "relacional", parte integrante do fazer inerente às relações públicas. Pensar as relações públicas para além das organizações, atuando pelo bem de indivíduos e grupos (formais e informais) por meio de suas contínuas transações e trocas é a contribuição que se busca aqui. 0 campo das relações públicas é um espaço contínuo de transformações que deve refutar perspectivas reducionistas de informação e persuasão, ou aquelas que posicionam a área de forma unicamente tecnicista. 0 reconhecimento da complexidade social das comunidades e a valorização da cidadania aproxima as relações públicas de um papel central para efetivas mudanças sociais (Kunsch, M.; Kunsch, W., 2007), distanciando o profissional de uma atuação meramente técnica.

Tratar o tema da comunicação comunitária sob o viés aqui proposto exige, portanto, entender o "comum" a que se refere a comunidade, que passa pelo acolhimento e reconhecimento do outro. Compreende-se, portanto, as relações públicas não como uma atividade de gestão de "grupos", mas como um modelo possível de gestão que "(re)conecte" os indivíduos por meio de atividades que têm o elemento relacional como o seu principal atributo.

\section{REFERÊNCIAS}

AUGÉ, Marc. Não-lugares: introdução a uma antropologia da sobremodernidade. 1ª edição francesa. Lisboa: 90 Graus, 1992.

BAUMAN, Zygmunt. Comunidade. Rio de Janeiro: Zahar, 2003. 
DUHRING, Lisa. Lost in translation? On the disciplinary status of public relations. Public Relations Inquiry, Sage Publications, v. 4, n.1, p. 5-23, 2015.

EDWARDS, Lee. Defining the object os public relations research: a new starting point. Public Relations Inquiry, v. 1, n.1, p.7-30, 2011.

ESPOSITO, Roberto. Communitas. origen y destino de la comunidad. Buenos Aires: Amorrortu, 2007.

FERREIRA, Maria Nazareth. A comunicação (des) integradora na América Latina: os contrastes do neoliberalismo. São Paulo: Edicon/Cebela, 1995.

FISCHER, Tânia ; SILVA, Francisco R. Moreira da ; SOARES, Rodrigo Maurício Freire. Bosque das Bromélias: mobilizações do presente, virtualidades do futuro - uma construção parentética. In: FERNANDES, Ana Cristina; LACERDA, Norma; PONTUAL, Virgínia (Orgs.). Desenvolvimento, planejamento e governança: expressões do debate contemporâneo. Rio de Janeiro: Letra Capital; Anpur, 2015. p. 201-222.

GRUNIG, James E.; HUNT, Todd. Managing public relations. New York: Holt, Rinehart \& Winston, 1984.

KUNSCH, Margarida M. Krohling; KUNSCH, Waldemar Luiz (Orgs.). Relações públicas comunitárias. a comunicação em uma perspectiva dialógica e transformadora. São Paulo: Summus Editorial, 2007.

MIANI, Rozinaldo. Comunicação popular. In: GADINI, Sérgio Luiz; WOITOWICZ, Karina Janz. Noções básicas de folkcomunicação. Ponta Grossa, PR: Editora UEPG, 2007.

PELBART, Peter P. A comunidade dos sem comunidade. In: PACHECO, Anelise; COCCO, Giuseppe; VAZ, Paulo (Orgs.). O trabalho da multidão. Rio de Janeiro: Gryphus, 2002. p. 93-108.

PEREIRA, Else Lemos Inácio. A era pós-disciplinar e o ambiente contemporâneo de relações públicas. cosmovisão ampliada da disciplina. Tese (Doutorado em Ciências da Comunicação) - Escola de Comunicações e Artes da Universidade de São Paulo, 2017.

PERUZZO, Cicilia M. Krohling. Comunicação nos movimentos populares. a participação na construção da cidadania. 3.ed. Petrópolis, RJ: Vozes, 2004.

SODRÉ, Muniz. Antropológica do espelho. Petrópolis: Vozes, 2002.

Texto recebido em 29.03.2017 e aprovado em 25.06.2017. 